\title{
Residue safety on ethephon in soybean leaf by drenching and foliar application
}

\author{
Seung-Heon Kong ${ }^{1} \cdot$ Deuk-Yeong Lee ${ }^{1} \cdot$ Young-Hoon Song ${ }^{1} \cdot$ Ki-Hun Park ${ }^{1}$. \\ Woo-Duck $\mathrm{Seo}^{2} \cdot$ Dong-Yeol Lee ${ }^{3} \cdot \mathrm{Jin}^{-H y o ~ \mathrm{Kim}^{1}}$
}

\section{에테폰의 관주처리와 엽면살포에 의한 콩 잎 중 잔류 안전성}

\author{
공숭헌 ${ }^{1}$ - 이득영 ${ }^{1}$ - 송영훈 ${ }^{1} \cdot$ 박기훈 $^{1}$ - 서우덕 ${ }^{2} \cdot$ 이동열 $^{3}$ - 김진효 ${ }^{1}$
}

Received: 9 December 2017 / Accepted: 21 February 2018 / Published Online: 31 March 2018

(C) The Korean Society for Applied Biological Chemistry 2018

\begin{abstract}
Ethephon is useful pesticide as ethylene precursor, which is an efficient plant hormone to produce functional secondary metabolites. However, the residual safety of ethephon was not studied on various crops. In here, the dissipation pattern of ethephon residue in soybean leaf was investigated both on the foliar and drenching applications. The biological half-lives of ethephon residues were 26.6 , and $21.1 \mathrm{~h}$ on the once, and double foliar applications, respectively. Although the residue after three days from the final application was up to $60.6 \mathrm{mg} \mathrm{kg}^{-1}$, the residue was below the limit of quantitation on the dried soybean leaf. In addition, drenching application of ethephon could increase the residue up to $36.3 \mathrm{mg} \mathrm{kg}^{-1}$ after $20.1 \mathrm{~h}$ from the application, however, the treatment would not affect to the total phenol content significantly $(p>0.01)$.
\end{abstract}

Jin Hyo Kim $(\bowtie)$

E-mail: jhkim75@gnu.ac.kr

${ }^{1}$ Division of Applied Life Science (BK21 plus), Institute of Agriculture and Life Science (IALS), Gyeongsang National University, Jinju 52828, Republic of Korea

${ }^{2}$ Crop Foundation Division, National Institute of Crop Science, Rural Development Administration, Wanju 55365, Republic of Korea

${ }^{3}$ Gyeongnam Oriental Medicinal Herb Institute, Sancheong, 52215, Republic of Korea

This is an Open Access article distributed under the terms of the Creative Commons Attribution Non-Commercial License (http://creativecommons. org/licenses/by-nc/3.0/) which permits unrestricted non-commercial use, distribution, and reproduction in any medium, provided the original work is properly cited.
Keywords Dissipation · Drenching · Ethephon · Foliar application Residue

\section{서 론}

Ethephon은 ethylene 전구체로 1965년 처음 개발되어 지금도 널 리 사용되는 농약이며, 국내에는 단감, 귤, 레몬, 면 종자, 밀, 배, 보리, 사과, 오이, 커피원두, 토마토, 파인애플, 포도, 피칸, 호두, 호박에 사용될 수 있도록 허가되어 있다. 이들에 대한 최 대잔류허용기준(MRL)은 $0.05-5.0 \mathrm{mg} \mathrm{kg}^{-1}$ 으로 설정되어 있지만 (KFDA 2017), 콩 잎 등 다수의 작물에 대한 ethephon 잔류허 용기준이 설정되어 있지 않아 ethephon을 농식품에 사용하는 상 업화 연구는 안전성에 대한 검증이 우선되어야 한다.

과거 기능성 물질 탐색 연구는 생물 소재로부터 새로운 물질 을 탐색하는 연구와 기능성을 검증하는 연구로 나뉘어 지난 수 십년 간 지속되어 왔으며, 이러한 연구를 통해 flavonoid, xanthone, anthocyanin, terpene, saponin 등 다양한 천연 물질의 구조와 기능성 등이 검증되어 왔다(Das 등, 2016, Rasheed 2016). 특 히, flavonoid와 같은 polyphenol계 물질은 높은 항산화력을 바 탕으로 항암, 항균, 항바이러스, 항염 등 다양한 질병 예방 및 치료 효과가 있는 것으로 알려져 상용화를 위한 대량 생산 연 구도 일부 진행되고 있다(Singh 등, 2009; Amatori 등, 2016; Gabbay Alves 등, 2017). 이러한 기능성 flavonoid 중 isoflavone 계열의 genistein, daidzein 등은 estrogen 유사물질로 항암, 뼈 건강, 항염증 등의 효능이 보고되었다(Duan 등, 2003; Mathey 등, 2007; Miao 등, 2012; de la Parra 등, 2016).

최근 천연 소재로부터 기능성 물질을 대량 생산하고자 하는 연구자들은 ethylene과 같은 식물 호르몬을 활용하는 연구를 진 
행하고 있고, 이들 중 작물 처리가 손쉬운 ethephon을 활용한 polyphenol 생산 연구가 다양하게 진행되고 있다(Miao 등, 2012; Teng과 Lee 2013; Kim등, 2015; de la Parra 등, 2016).

최근 Yuk 등(2016)은 대두 콩 잎으로부터 isoflavone을 대량 생산하는데 성공하였으며, 이를 위해 식물호르몬인 ethylene을 개화기 직전에 처리하는 방법을 사용하였다. 이 연구에서 Yuk 등(2016)은 실험실이 아닌 포장시험에서의 ethylene 처리는 ethephon을 경엽살포하는 방법을 사용하였다. 하지만, ethephon 은 콩 잎에서 잔류허용기준이 설정되어 있지 않고, 콩 잎 재배 중 ethephon 잔류 감소에 관한 연구가 전혀 보고된 바가 없다. 따라서, 본 연구에서는 콩 잎 생산과정 중 ethephon을 경엽살 포 혹은 관주 처리시 콩 잎 중 잔류 감소 변화를 조사하고, 수 확 후 건조된 콩 잎 시료에서 ethephon 잔류 안전성을 평가하 여, 기능성 polyphenol 생산을 위해 처리한 ethephon의 안전성 을 확인하고자 하였다.

\section{재료 및 방법}

\section{시약 및 기구}

Ethephon 잔류 안전성 시험을 위하여 사용한 분석용 표준품과 유도체 시약인(trimethylsilyl) diazomethane solution (2.0 M in diethyl ether)과 Folin-Ciocalteu's phenol은 Sigma-aldrich Co. Ltd. (St. Louis, MO, USA)로부터 구입하여 사용하였으며, 전처 리에 사용한 용매인 acetonitrile과 acetone은 Merck Co. (Darmstadt, German)에서 구입하였다. 또한, total flavonoid 와 total phenol 분석을 위하여 사용한 ethanol은 Fisher Scientific Co. (Hampton, VI, USA) 제품을 사용하였으며, aluminum chloride 와 sodium acetate, sodium carbonate는 Shinyo Pure Chemicals Co. (Hyogo, Japan)에서 구입하여 사용하였다. 시험포장에서 사 용된 약제는 AgroTech Co. (Seoul, Republic of Korea)의 에 테폰 액제(A.I. $39 \%$ )를 시중에서 구매하여 사용하였다.

\section{Ethephon 경엽처리}

2016년 7월 경남 진주시 미천면 안간리 시험포장에서 본 연구 를 실시하였다. Yuk 등(2016)의 연구결과를 토대로 개화기 전 콩에 에테폰 액제 400 배 희석액을 $24 \mathrm{~h}$ 간격으로 각각 1 회와 2 회 살포하였으며, 약액 살포량은 $300 \mathrm{~mL} 10 \mathrm{a}^{-1}$ 이었다. 최종 살 포 $2 \mathrm{~h}$ 후 부터 $72 \mathrm{~h}$ 경과 시까지 콩 잎 시료를 수확하여 수확 된 콩 잎 중 ethephon 잔류변화를 평가하였다. 시험포장에서 수 확된 콩 잎은 아이스 박스에 담아 실험실로 옮긴 후 수확 $1 \mathrm{~h}$ 내 드라이아이스와 함께 동결 분쇄하였고, $-20^{\circ} \mathrm{C}$ 에서 냉동 보 관하며 잔류 분석에 사용하였다.

\section{Ethephon 관주처리}

2017년 7월 경남 진주시 경상대학교 부속농장에서 $1 / 5000 \mathrm{a}$ 와 그너포트를 사용하여 개화기 전 콩에 에테폰 액제 200배와 400 배 희석액을 포트 당 $200 \mathrm{~mL}$ 씩 1회 처리하고 약액 처리 $2 \mathrm{~h}$ 후 부터 $36 \mathrm{~h}$ 경과시 까지 콩 잎 시료를 수확하였으며, $1 \mathrm{~h}$ 이 내에 드라이아이스를 사용하여 동결 분쇄하고, $-20{ }^{\circ} \mathrm{C}$ 에서 냉동 보관하며 잔류 분석에 사용하였다.
Table 1 Instrumental condition of GC-MSD for the quantitative analysis of ethephon

\begin{tabular}{|c|c|c|c|c|}
\hline Instrument & \multicolumn{4}{|c|}{ Agilent $7890 \mathrm{~A}$ with autosampler } \\
\hline Column & \multicolumn{4}{|c|}{$\begin{array}{l}\text { Agilent DB-35 Capillary Column, } 30 \mathrm{~m} \times 250 \mu \mathrm{m} \text {, } \\
0.25 \mu \mathrm{m}\end{array}$} \\
\hline Detector & \multicolumn{4}{|c|}{$5975 \mathrm{C}$ mass spectrometry, temperature $270^{\circ} \mathrm{C}$} \\
\hline Temperature & \multicolumn{4}{|c|}{ Inlet: $180^{\circ} \mathrm{C}$, Source: $200^{\circ} \mathrm{C}$, Quad: $150^{\circ} \mathrm{C}$} \\
\hline \multirow{5}{*}{ Oven condition } & Temp $\left({ }^{\circ} \mathrm{C}\right)$ & Rate $\left({ }^{\circ} \mathrm{C} / \mathrm{mir}\right.$ & Hold (min) & Total (min) \\
\hline & 100 & & 2.00 & 2.00 \\
\hline & 130 & 10.00 & 2.00 & 10.00 \\
\hline & 150 & 15.00 & 0.00 & 30.00 \\
\hline & 290 & 30.00 & 3.00 & 37.67 \\
\hline Injection volume & \multicolumn{4}{|c|}{$1 \mu \mathrm{L}($ Split $10: 1)$} \\
\hline $\begin{array}{l}\text { Ion mass-to-charge } \\
\text { (SIM) }\end{array}$ & \multicolumn{4}{|c|}{110 (quantitative ion), 109 (qualitative ion) } \\
\hline
\end{tabular}

\section{Ethephon 잔류분석}

Ethephon 잔류분석은 Takenaka(2002)의 방법에 따라 gas chromatography-mass spectrometry (GC-MSD)을 사용하여 다음 과 같이 분석하였다. 동결 분쇄된 콩 잎 시료 $1.0 \mathrm{~g}$ 을 $15 \mathrm{~mL}$ conical tube에 $0.1 \mathrm{M} \mathrm{HCl}$ 이 포함된 acetonitrile $10.0 \mathrm{~mL}$ 를 넣 어 30 분 동안 $170 \mathrm{rpm}$ 에서 진탕 추출하였다. 추출 시료는 원심 분리 $\left(4000 \mathrm{rpm}, 10 \mathrm{~min}, 4{ }^{\circ} \mathrm{C}\right)$ 후 상등액 $1.0 \mathrm{~mL}$ 를 취하고, $1.0 \mathrm{~mL}$ (trimethylsilyl) diazomethane solution으로 상온에서 30 분간 methylation 하였다. 유도체화 된 시료는 질소농축기를 이 용하여 농축하였고, 농축된 시료를 acetone $1.0 \mathrm{~mL}$ 로 재용해한 뒤 $0.22 \mu \mathrm{m}$ syringe filter로 여과 후 GC-MSD (Agilent Co., Santa Clara, CA, USA)로 분석하였다. 상세한 기기분석 조건은 Table 1에 나타내었다.

\section{Ethephon 잔류분석법 검중}

Ethephon 표준물질은 acetone을 이용하여 $1,000 \mathrm{mg} \mathrm{L}^{-1}$ stock solution 을 제조한 후 $0.05,0.1,0.5,1.0,2.0,5.0,10.0 \mathrm{mg} \mathrm{L}^{-1}$ 농도 로 working solution을 제조하고 $1.0 \mathrm{~mL}$ working solution에 (trimethylsilyl)diazomethane solution $1.0 \mathrm{~mL}$ 를 넣어 methylation 하였다. Methylation 된 표준용액은 질소 기류 하에서 농축 후 acetone $1.0 \mathrm{~mL}$ 로 재용해 후 GC-MS로 분석하였으며, 3반복 시 험 후 평균값을 사용하여 ethephon 표준검량선을 작성하였다. 표준검량선의 $\mathrm{r}^{2}$ 는 0.9998 로 나타났고, 콩 잎에서 ethephon 정 량한계(limit of quantitation, $\mathrm{LOQ}$ )는 $0.05 \mathrm{mg} \mathrm{kg}^{-1}$ 이었다. 회수 율 시험은 1.0 과 $5.0 \mathrm{mg} \mathrm{kg}^{-1}$ 두 수준에서 실시하여 $105.1 \%$ 와 $104.5 \%$ 로 확인되었고, 시험 분석간 상대표준편차는 $4.1 \%$ 로 정 량잔류분석에 적합하였다.

\section{건조 콩 잎 제조}

수확된 콩 잎은 $60^{\circ} \mathrm{C}$ 로 유지되는 dry oven에서 펼친 상태로 $24 \mathrm{~h}$ 동안 건조하였으며, 건조된 콩 잎은 믹서기로 분쇄하여 분 석에 사용하였다.

\section{Total phenol 분석}

Total phenol 분석은 Yuk 등(2016)이 사용한 Folin-Denis법을 


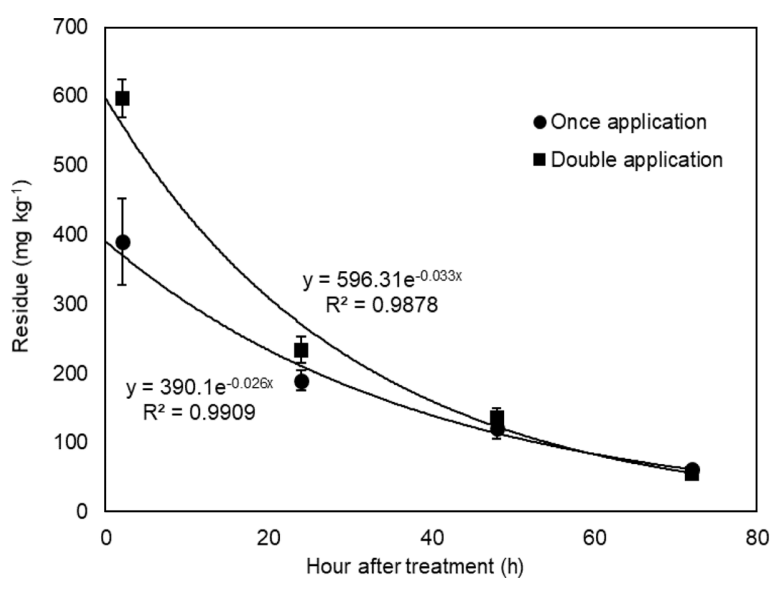

Fig. 1 Dissipation pattern of ethephon residue in soybean leaf by foliar application

Table 2 Dissipation regression equation and half-life of ethephon residue in soybean leaf

\begin{tabular}{clc}
\hline \hline & $\begin{array}{c}\text { Dissipation regression } \\
\text { equation }\end{array}$ & $\begin{array}{c}\text { Biological } \\
\text { half-life }(\mathrm{h})\end{array}$ \\
\hline Once application & $\mathrm{y}=390.1 \mathrm{e}^{-0.026 \mathrm{x}}\left(\mathrm{r}^{2} 0.9909\right)$ & 26.6 \\
Double application & $\mathrm{y}=596.31 \mathrm{e}^{-0.033 \mathrm{x}}\left(\mathrm{r}^{2} 0.9878\right)$ & 21.1 \\
\hline
\end{tabular}

사용하였다. 건조 콩잎 $0.20 \mathrm{~g}$ 을 $70 \%$ ethanol 수용액 $10.0 \mathrm{~mL}$ 에 넣은 후 $24 \mathrm{~h}$ 동안 진탕 추출하였다. 이후 원심분리(4000 $\mathrm{rpm}, 10 \mathrm{~min}, 4{ }^{\circ} \mathrm{C}$ )하여 상등액 $0.1 \mathrm{~mL}$ 를 test tube에 분취하고 Folin-Ciocateu's phenol $0.5 \mathrm{~mL}$ 와 $1 \%$ sodium carbonate 1.0 $\mathrm{mL}$ 를 첨가하여 1 분간 중탕 후 상온의 암조건에서 15 분간 식힌 뒤 $685 \mathrm{~nm}$ 에서 흡광분석하였다. Total phenol 분석의 기준물질 은 quercetin (Sigma-Aldrich Co.)를 사용하였다.

\section{통계 분석}

Total phenol 분석결과에 대한 신뢰성 분석은 총 9회 반복 시험 결과를 바탕으로 통계프로그램 R (ver. 3.2.4, R Foundation, Austria)을 사용하여 tukey test를 통해 유의수준 0.01 에서 검정 하였다.

\section{결과 및 고찰}

\section{경엽살포 후 콩 잎 중 ethephon 잔류양상}

Yuk 등(2016)은 에테폰 액제를 400배 희석 후 경엽 살포하였다. 따라서, 본 연구에서는 이와 동일한 시험 조건인 $39 \%$ 에테폰 액제를 400 배 희석하여 1회 처리와 $24 \mathrm{~h}$ 간격 2회 처리로 구 분하여 ethephon 잔류특성을 알아보고자 하였다. Ethephon의 초 기 잔류량은 1회와 2회 살포하였을 때 각각 $395.8,596.3 \mathrm{mg}$ $\mathrm{kg}^{-1}$ 으로 나타났으며(Fig. 1), 생물학적 반감기는 각각 $26.6 \mathrm{~h}$ 및 $21.1 \mathrm{~h}$ 로 나타났다(Table 2). Yuk 등(2016)은 최종 약제 처리 3 일 후 isoflavone 생성량이 우수하다고 보고 하였으며, 여기서 제시한 수확 시점에 수확된 콩 잎 중 ethephon 잔류량은 1회 처리구와 2회 처리구에서 각각 $54.6,60.7 \mathrm{mg} \mathrm{kg}$ 으로 확인되

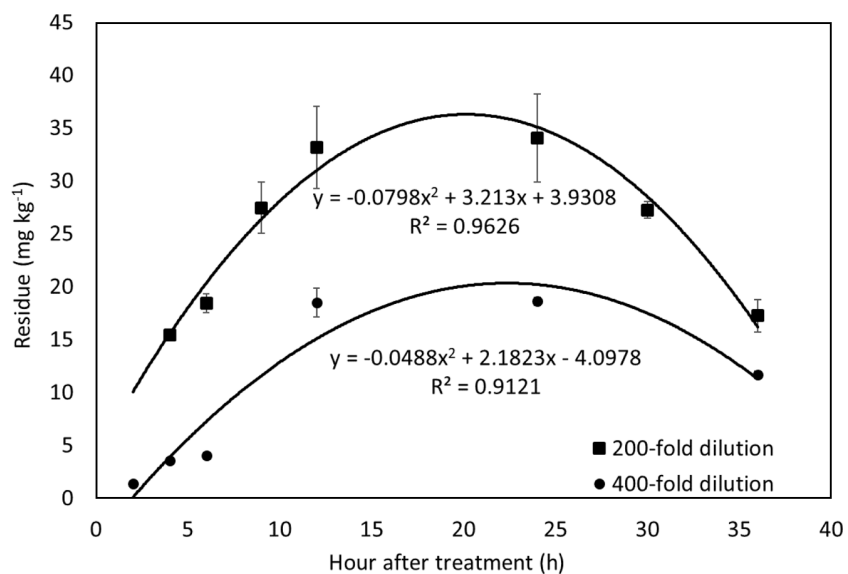

Fig. 2 Dissipation pattern of ethephon residue in the leaf of soybean by drenching application

었다. 하지만, 수확 후 $24 \mathrm{~h}$ 동안 건조된 콩 잎에서는 ethephon 잔류가 $\mathrm{LOQ}$ 미만으로 확인되었다. 따라서, isoflavone 고함유 콩 잎 생산 시 최소한의 잔류안전성이 확보될 수 있도록 생산 된 콩 잎은 반드시 $24 \mathrm{~h}$ 이상 건조하여 콩 잎 중 잔류 ethephon 을 제거한 후 식품원료로 사용해야 할 것이다.

\section{관주처리 후 콩 잎 중 ethephon 잔류양상}

Ethephon 관주 처리시 잔류특성을 알아보기 위해 처리약제의 희석배수는 작물 생육에 큰 지장을 주지 않는 고농도 구간을 찾기 위해, $39 \%$ 에테폰 액제에 대해 $50-400$ 배 희석액을 각각 포트 당 $200 \mathrm{~mL}$ 처리하였고, 약해가 나타나지 않는 400배와 200 배 희석액을 시험농도 구간으로 선정하였다. 콩 잎에서 ethephon의 잔류농도는 $20 \mathrm{~h}$ 경과 시까지 지속적으로 증가하는 양상을 나타내었으며, 400배와 200배 희석액 처리시 ethephon 의 최대 잔류 농도는 각각 $20.3 \mathrm{mg} \mathrm{kg}$ 과 $36.3 \mathrm{mg} \mathrm{kg}^{-1}$ 으로 나 타났으며, 최대 잔류농도까지 도달하는 시간은 $22.3 \mathrm{~h}$ 과 $20.1 \mathrm{~h}$ 으로 각각 나타났다(Fig. 2). 본 시험에 적용된 관주 처리의 경 우 콩 잎 중 최대 잔류농도가 경엽 살포보다 최소 10 배 이상 낮았으나, 총 polyphenol 분석결과 기능성 물질의 함량은 무처 리구 $\left(1,347 \mathrm{mg} 100 \mathrm{~g}^{-1}\right)$ 와 비교하여 관주처리 시험구(1280-1322 $\left.\mathrm{mg} 100 \mathrm{~g}^{-1}\right)$ 와 유의적 차이가 확인되지 않았다 $(p>0.01)$. 따라서, 관주 처리는 콩 잎 중 ethephon 잔류에 영향을 주지만, 콩 잎 중 isoflavone과 같은 polyphenol 생산에서 주목할 만한 결과를 나타내지 않았다.

\section{초 록}

식물생장호르몬인 에틸렌의 전구체인 에테폰은 기체상의 에틸 렌을 대신하여 가장 빈번히 사용되는 농약 중 하나로, 식물 이 차 대사산물의 생산에 사용되고 있다. 최근 콩잎으로부터 식물 이차 대사산물인 이소플라본 생산에 에틸렌 및 에테폰 처리에 관한 연구가 시도되었으나, 에테폰의 잔류안전성에 관한 연구가 보고되지 못하였다. 이에 본 연구는 콩잎 생산시 에테폰을 경 엽과 관주 처리하여 나타나는 잔류 변화를 연구하였다. 경엽 처 
리시 콩잎 중 에테폰의 잔류반감기는 1회와 2회 처리시 $26.6 \mathrm{~h}$ 과 $21.1 \mathrm{~h}$ 으로 확인되었고, 처리 3일 후 콩잎 중 에테폰은 최대 $60 \mathrm{mg} \mathrm{kg}$-1이었으나, 콩잎 건조 후 에테폰은 불검출 되었다. 관 주 처리시 $20.1 \mathrm{~h}$ 후 최대 잔류농도가 관찰되었으나, 관주처리 에 의한 Total phenol 함량 변화는 관찰되지 않았다.

Keywords 반감기 · 안전성 · 에테폰 · 잔류 · 콩잎

Acknowlegment This study was carried out with the support of "Cooperative Research Program for Agricultural Science \& Technology Development (Project No. PJ01251002)", Rural Development Administration, Republic of Korea.

\section{References}

Amatori S, Mazzoni L, Alvarez-Suarez JM, Giampieri F, Gasparrini M, Forbes-Hernandez TY, Afrin S, Provenzano AE, Persico G, Mezzetti B, Amici A, Fanelli M, Battino M (2016) Polyphenol-rich strawberry extract (PRSE) shows in vitro and in vivo biological activity against invasive breast cancer cells. Sci Rep 6: 30917

de la Parra C, Castillo-Pichardo L, Cruz-Collazo A, Cubano L, Redis R, Calin GA, Dharmawardhane S (2016) Soy Isoflavone Genistein-Mediated Downregulation of miR-155 Contributes to the Anticancer Effects of Genistein. Nutr Cancer 68: 154-164

Das S, Stark L, Musgrave IF, Pukala T, Smid SD (2016) Bioactive polyphenol interactions with beta amyloid: a comparison of binding modelling, effects on fibril and aggregate formation and neuroprotective capacity. Food Funct 7: 1138-1146

Duan W, Kuo IC, Selvarajan S, Chua KY, Bay BH, Wong WS (2003) Antiinflammatory effects of genistein, a tyrosine kinase inhibitor, on a guinea pig model of asthma. Am J Respir Crit Care Med 167: 185-192

Gabbay Alves TV, Silva da Costa R, Aliakbarian B, Casazza AA, Perego P, Pinheiro Arruda MS, Carrera Silva Junior JO, Converti A, Ribeiro Costa
RM (2017) Bioactive compounds and antioxidant potential for polyphenol-rich cocoa extract obtained by agroindustrial residue. Nat Prod Res 1-4

KFDA (2017) Ethephon in Pesticides and veterinary drugs information, Korea Food \& Drug Administration, Cheongju, Republic of Korea. Website available: http://www.foodsafetykorea.go.kr/residue/search/list.do? currentPageNo=1\&searchType $=\&$ searchValue $=$ ethephon\&searchFlag=A LL (accessed on Dec. 05, 2017)

Kim MJ, Kim JH, Kim JH, Kim YJ (2015) Comparative studies on the antioxidant capacities and catechin profiles of conventional and organic green tea. J Kor Soc Appl Biol Chem 58: 475-480

Mathey J, Mardon J, Fokialakis N, Puel C, Kati-Coulibaly S, Mitakou S, Bennetau-Pelissero C, Lamothe V, Davicco MJ, Lebecque P, Horcajada MN, Coxam V (2007) Modulation of soy isoflavones bioavailability and subsequent effects on bone health in ovariectomized rats: the case for equol. Osteoporos Int 18: 671-679

Miao Q, Li JG, Miao S, Hu N, Zhang J, Zhang S, Xie YH, Wang JB, Wang SW (2012) The bone-protective effect of genistein in the animal model of bilateral ovariectomy: roles of phytoestrogens and PTH/PTHR1 against post-menopausal osteoporosis. Int J Mol Sci 13: 56-70

Rasheed Z (2016) Green Tea Bioactive Polyphenol Epigallocatechin-3-OGallate in Osteoarthritis: Current Status and Future Perspectives. Int J Health Sci (Qassim) 10: V-VIII

Singh S, Jarret R, Russo V, Majetich G, Shimkus J, Bushway R, Perkins B (2009) Determination of capsinoids by HPLC-DAD in capsicum species. J Agric Food Chem 57: 3452-3457

Takenaka S (2002) New method for ethephon ((2-chloroethyl)phosphonic acid) residue analysis, and detection of residual levels in the fruit and vegetables of Western Japan. J Agric Food Chem 50: 7515-7519

Teng H, Lee WY (2013) Optimization of microwave-assisted extraction of polyphenols from mulberry fruits (Morus alba L.) using response surface methodology. J Kor Soc Appl Biol Chem 56: 317-324

Yuk HJ, Song YH, Curtis-Long MJ, Kim DW, Woo SG, Lee YB, Uddin Z, Kim CY, Park KH (2016) Ethylene Induced a High Accumulation of Dietary Isoflavones and Expression of Isoflavonoid Biosynthetic Genes in Soybean (Glycine max) Leaves. J Agric Food Chem 64: 7315-7324 